\title{
Correction to: Dimensions of leisure-time physical activity and risk of depression in the "Seguimiento Universidad de Navarra" (SUN) prospective cohort
}

\author{
Alejandro Fernandez-Montero ${ }^{1,2,3^{*}}$, Laura Moreno-Galarraga ${ }^{2,3,4}$, Almudena Sánchez-Villegas5,6, \\ Francisca Lahortiga-Ramos ${ }^{3,7}$, Miguel Ruiz-Canela ${ }^{2,3,6}$, Miguel Ángel Martínez-González 23,6,8 and Patricio Molero
}

\section{Correction to: BMC Psychiatry \\ https://doi.org/10.1186/s12888-020-02502-6}

After publication of our article [1] we have been notified that Table 2 was incorrectly formatted.

- Originally published version:

Table 2 Depression risk according to different dimensions of baseline physical activity. The SUN Project 1999-2018

\begin{tabular}{|c|c|c|c|c|}
\hline $\begin{array}{l}\text { Total leisure-time physical activity } \\
\text { (MET-h/wk) }\end{array}$ & & & & $<10 \mathrm{MET}-\mathrm{h} / \mathrm{wk}$ \\
\hline Depression cases / person-years & $366 / 59193$ & 10 to $20 \mathrm{MET}-\mathrm{h} / \mathrm{wk}$ & $>20 \mathrm{MET}-\mathrm{h} / \mathrm{wk}$ & $P$ for trend \\
\hline Multivariable-adjusted HR ${ }^{a}$ (95\% Cl) & 1 (ref.) & 193/37606 & $311 / 66260$ & \\
\hline Time spent in leisure time physical activity (hours/wk) & $<75 \mathrm{~min} / \mathrm{wk}$ & $0.88(0.74-1.05)$ & $0.84(0.72-0.99)$ & 0.046 \\
\hline Events / person-years & $279 / 44420$ & $75-300 \mathrm{~min} / \mathrm{wk}$ & $>300 \mathrm{~min} / \mathrm{wk}$ & \\
\hline Multivariable-adjusted $\mathrm{HR}^{\mathrm{b}}(95 \% \mathrm{Cl})$ & 1 (ref.) & $345 / 65624$ & $246 / 53015$ & \\
\hline Intensity in leisure time physical activity (average METS) & Inactive & $0.88(0.75-1.04)$ & $0.83(0.70-0.99)$ & 0.057 \\
\hline Events / person-years & $161 / 26004$ & $<6$ Average METs & $\geq 6$ Average METs & \\
\hline Multivariable-adjusted $\mathrm{HR}^{\mathrm{C}}(95 \% \mathrm{Cl})$ & 1 (ref.) & $574 / 110834$ & $135 / 26220$ & \\
\hline
\end{tabular}

${ }^{2}$ Adjusted for sex, baseline body mass index, time sleeping, time nap, time TV, total energy intake, adherence to the Mediterranean Diet, alcohol intake, smoking pack years, educational level, hypertension, diabetes mellitus, cancer and changes in physical activity in the 2th and 4th year follow-up, with age and year of entering the cohort as stratification variables

${ }^{\mathrm{b}}$ Additional adjusted by intensity physical activity

${ }^{\mathrm{C}}$ Additional adjusted by leisure time physical activity

The original article can be found online at https://doi.org/10.1186/s13063019-3709-5

* Correspondence: afmontero@unav.es

${ }^{1}$ Department of Occupational Medicine, University of Navarra Clinic, Av. Pio

XII, 36, 31008 Pamplona, Navarra, Spain

${ }^{2}$ Department of Preventive Medicine and Public Health, University of Navarra,

Pamplona, Spain

Full list of author information is available at the end of the article

(c) The Author(s). 2020 Open Access This article is licensed under a Creative Commons Attribution 4.0 International License, which permits use, sharing, adaptation, distribution and reproduction in any medium or format, as long as you give appropriate credit to the original author(s) and the source, provide a link to the Creative Commons licence, and indicate if changes were made. The images or other third party material in this article are included in the article's Creative Commons licence, unless indicated otherwise in a credit line to the material. If material is not included in the article's Creative Commons licence and your intended use is not permitted by statutory regulation or exceeds the permitted use, you will need to obtain permission directly from the copyright holder. To view a copy of this licence, visit http://creativecommons.org/licenses/by/4.0/. The Creative Commons Public Domain Dedication waiver (http://creativecommons.org/publicdomain/zero/1.0/) applies to the data made available in this article, unless otherwise stated in a credit line to the data. 
- Correct version:

Table 2 Depression risk according to different dimensions of baseline physical activity. The SUN Project 1999-2018

\begin{tabular}{|c|c|c|c|c|}
\hline Total leisure-time physical activity (MET-h/wk) & $<10$ MET-h/wk & 10 to $20 \mathrm{MET}-\mathrm{h} / \mathrm{wk}$ & $>20 \mathrm{MET}-\mathrm{h} / \mathrm{wk}$ & $P$ for trend \\
\hline Depression cases / person-years & $366 / 59193$ & $193 / 37606$ & $311 / 66260$ & \\
\hline Multivariable-adjusted $\mathrm{HR}^{\mathrm{a}}(95 \% \mathrm{Cl})$ & 1 (ref.) & $0.88(0.74-1.05)$ & $0.84(0.72-0.99)$ & 0.046 \\
\hline Time spent in leisure time physical activity (hours/wk) & $<75 \mathrm{~min} / \mathrm{wk}$ & $75-300 \mathrm{~min} / \mathrm{wk}$ & $>300 \mathrm{~min} / \mathrm{wk}$ & \\
\hline Events / person-years & $279 / 44420$ & $345 / 65624$ & $246 / 53015$ & \\
\hline Multivariable-adjusted $\mathrm{HR}^{\mathrm{b}}(95 \% \mathrm{Cl})$ & 1 (ref.) & $0.88(0.75-1.04)$ & $0.83(0.70-0.99)$ & 0.057 \\
\hline Intensity in leisure time physical activity (average METS) & Inactive & $<6$ Average METs & $\geq 6$ Average METs & \\
\hline Events / person-years & $161 / 26004$ & $574 / 110834$ & $135 / 26220$ & \\
\hline Multivariable-adjusted HR c $(95 \%$ Cl) & 1 (ref.) & $0.90(0.75-1.09)$ & $1.00(0.79-1.27)$ & 0.650 \\
\hline
\end{tabular}

${ }^{a}$ Adjusted for sex, baseline body mass index, time sleeping, time nap, time TV, total energy intake, adherence to the Mediterranean Diet, alcohol intake, smoking pack years, educational level, hypertension, diabetes mellitus, cancer and changes in physical activity in the 2th and 4th year follow-up, with age and year of entering the cohort as stratification variables

${ }^{\mathrm{b} A d d i t i o n a l ~ a d j u s t e d ~ b y ~ i n t e n s i t y ~ p h y s i c a l ~ a c t i v i t y ~}$

'Additional adjusted by leisure time physical activity

The original article has been corrected.

\section{Author details}

'Department of Occupational Medicine, University of Navarra Clinic, Av. Pio XII, 36, 31008 Pamplona, Navarra, Spain. ${ }^{2}$ Department of Preventive Medicine and Public Health, University of Navarra, Pamplona, Spain. ${ }^{3}$ IdiSNA (Instituto de Investigación Sanitaria de Navarra), Pamplona, Spain. ${ }^{4}$ Department of Pediatrics, Complejo Hospitalario de Navarra, Servicio Navarro de Salud, Pamplona, Spain. ${ }^{5}$ Nutrition Research Group, Research Institute of Biomedical and Health Sciences, University of Las Palmas de Gran Canaria, Las Palmas de Gran Canaria, Spain. ${ }^{6}$ CIBER Fisiopatología de la Obesidad y Nutrición (CIBER Obn), Instituto de Salud Carlos III, Madrid, Spain. ${ }^{7}$ Department of Psychiatry and Medical Psychology, University Clinic of Navarra, Pamplona, Spain.

${ }^{8}$ Department of Nutrition, Harvard TH Chan School of Public Health, Boston, USA.

Published online: 23 March 2020

\section{Reference}

1. Fernandez-Montero A, et al. Dimensions of leisure-time physical activity and risk of depression in the "Seguimiento Universidad de Navarra" (SUN) prospective cohort. BMC Psychiatry. 2020;20:98. https://doi.org/10.1186/ s12888-020-02502-6. 